\title{
Development of a set of process and structure indicators for palliative care: the Europall project
}

\author{
Kathrin Woitha ${ }^{1 *}$, Karen Van Beek ${ }^{2}$, Nisar Ahmed ${ }^{3}$, Jeroen Hasselaar ${ }^{1}$, Jean-Marc Mollard ${ }^{5}$, Isabelle Colombet ${ }^{6,7}$, \\ Lukas Radbruch $^{4}$, Kris Vissers ${ }^{1}$ and Yvonne Engels ${ }^{1}$
}

\begin{abstract}
Background: By measuring the quality of the organisation of palliative care with process and structure quality indicators (QIs), patients, caregivers and policy makers are able to monitor to what extent recommendations are met, like those of the council of the WHO on palliative care and guidelines. This will support the implementation of public programmes, and will enable comparisons between organisations or countries.

Methods: As no European set of indicators for the organisation of palliative care existed, such a set of Qls was developed. An update of a previous systematic review was made and extended with more databases and grey literature. In two project meetings with practitioners and experts in palliative care the development process of a QI set was finalised and the Qls were categorized in a framework, covering the recommendations of the Council of Europe.

Results: The searches resulted in 151 structure and process indicators, which were discussed in steering group meetings. Of those Qls, 110 were eligible for the final framework.

Conclusions: We developed the first set of Qls for the organisation of palliative care. This article is the first step in a multi step project to identify, validate and pilot Qls.
\end{abstract}

Keywords: Quality indicator, Organisation, Europe, Public health, Palliative care, Europall

\section{Background}

Following the 2002 definition of the World Health Organisation (WHO), palliative care is no longer restricted to patients with cancer; it should be available for all patients with life-threatening diseases [1]. Furthermore, palliative care is applicable early in the course of the disease and can be delivered in conjunction with interventions that aim to prolong life. Palliative care needs a team approach in order to relieve not only pain and other somatic symptoms but also to provide multi-dimensional care including psychosocial and spiritual care and support for patients and their proxies. This wider definition implies an increase of the number of patients eligible for palliative care. Due to successful medical interventions, the aging population and improved survival of patients with chronic diseases or

\footnotetext{
*Correspondence: k.woitha@anes.umcn.nl

'Department of Anaesthesiology, Pain and Palliative Medicine, Radboud University Nijmegen Medical Centre, Geert Grote Plein 10, Nijmegen 6500 $H B$, The Netherlands

Full list of author information is available at the end of the article
}

with cancer, the demand for palliative care will increase too $[2,3]$.

In 2003, the Council of Europe launched recommendations for the organisation of palliative care regarding settings and services, policy and organisation, quality improvement and research, education and training, family, communication with the patient and family, teams and bereavement. This included further cooperation between European countries [4]. As most scientific studies focus on clinical outcomes, it is unclear whether these recommendations and the WHO definition have been implemented in the organisation of palliative care in Europe. By measuring the quality of the organisation of palliative care, patients, caregivers and policy makers can monitor whether in their country, specific settings and networks for palliative care meet the recommendations of the council of Europe and of the WHO. This information would give better insight, which is needed for the measurement of the impact of palliative care programs [5].

\section{C) Biomed Central}


A valid and reliable method for assessing the quality of the organisation of care is the use of structure and process quality indicators (QIs). QIs are 'explicitly defined and measurable items referring to the outcomes, processes or structure of care' [6,7]. In a systematic review published in 2009, clinical indicators appeared to be widely overrepresented over indicators that assess organisational issues of palliative care, and most QIs were developed in and for one specific country or setting [8].

Therefore, we aimed to develop a scientifically sound European set of structure and process QIs, as a first step in quality measurement and improvement.

\section{Methods}

The study, undertaken by partners from seven collaborating countries (Belgium, United Kingdom, France, Germany, Netherlands, Poland and Spain), ran from October 2007 till September 2010 [9]. It was co-funded by the European Executive Agency for Health and Consumers (EAHC).

QI sets can be based on existing sets of QIs, recommendations from clinical guidelines, scientific literature, best practice or expert consensus [6]. We used a combination of these.

As palliative care, being a relatively young field within health care is changing rapidly. The initial phase of this project was an update and extension of a previous review aiming to find already existing QIs in literature or aspects of the organisation of the palliative care for which QIs would be useful [8]. QIs were operationalized as 'measurable items referring to the outcomes, processes or structure of care' [6,7]. Organisation of palliative care was defined as 'systems to enable the delivery of good quality in palliative care', which made us focus on processes and structures [7]. Besides publications that describe the development or use of QIs for the organisation of palliative care, publications were used that describe the structure or process of good palliative care, in order to develop QIs if not available yet.

\section{Main database search}

As an update and extension of an existing systematic review, the following bibliographic databases were searched: Medline, Scopus, PsycINFO, Social Medicine, CINAHL, the Cochrane Database, Embase, SIGLE, ASCO, and Google Scholar by an existing search strategy (Additional file 1: Appendix A) [8]. If applicable, Mesh terms were changed, as these are database-specific.

Inclusion criteria were a publication period from December 2007 to May 2009, as the systematic review ran until December 2007 and containing information about the development or use of (sets of) QIs.

Papers describing QIs about palliative care for children, clinical outcome indicators, patient outcome and on treatment were excluded, as well as scientific papers that were not written in English.

The initial selection process was based on independent screening by three researchers of title and/or abstract, followed by a selection based on full text. Additionally, reference lists of obtained papers were studied and hand searches were performed (Current Opinion in Supportive and Palliative Care, Journal of Pain and Symptom Management, Palliative Medicine and Quality and Safety in Health Care Journal).

The QIs derived from the search were categorized in a framework. It was based on (1) a previously developed framework for evalution of the organisation of general practice and adapted for palliative care and (2) the recommendations of the Council of Europe $[4,10]$. It contains the domains 1. Definition of a palliative care service, 2. Access to palliative care, 3. Infrastructure, 4. Assessment tools, 5. Personnel, 6. Documentation of clinical data, 7. Quality and safety issues, 8. Reporting clinical activity of palliative care, 9. Research and 10. Eduation.

\section{Grey literature search}

If a domain or subdomain of the framework was not covered with QIs found in the literature search, an additional grey literature search was performed. Grey literature was defined as 'literature which has not been formally published in peer- reviewed literature' [11]. Inclusion of grey literature was restricted to reports from government agencies or scientific research groups, white papers and websites from national organisations of the seven participating countries. Finally, the network of the Europall research group was used to identify relevant papers.

\section{Methods of screening and article selection}

The steering group of the Europall project planned two meetings in September and October 2009 with all project members (Additional file 1: Appendix B).

\section{QI selection}

The draft set of structure and process QIs was discussed during the first steering group meeting in September 2009. Academic experts from several disciplines in palliative care, all from one of the seven participating European countries were invited. Consensus was based on 1 . whether it considered a process or structure QI 2. whether it overlapped with other proposed QIs, 3. to which domain of the framework (Table 1) it belonged [10] and 4. for which settings it was applicable. Based on the grey literature search, the project partners could suggest new QIs about aspects that were relevant but not yet operationalised as QIs. 


\section{Definition of a palliative care service}

1 All the services below are part of a comprehensive palliative care service: Palliative day care, Palliative home care support team, Hospice beds, Palliative hospital support team, Inpatient palliative care hospital beds, Palliative care outpatient clinic, Bereavement support

2 All the services below are part of a comprehensive palliative care service: Palliative day care

3 All the services below are part of a comprehensive palliative care service: Palliative home care support team

$4 \quad$ All the services below are part of a comprehensive palliative care service: Hospice beds

5 All the services below are part of a comprehensive palliative care service: Palliative hospital support team

6 All the services below are part of a comprehensive palliative care service: Inpatient palliative care hospital beds (e.g. palliative care unit)

$7 \quad$ All the services below are part of a comprehensive palliative care service: Palliative care outpatient clinic

8 All the services below are part of a comprehensive palliative care service: Bereavement support

Access to palliative care

\section{A. Access and availability (All settings)}

9 A palliative care team is available at the request of the treating professional/team in all of the following settings: Day care, at home, Hospital, Hospice, Nursing home, Outpatient clinic, Day care

10 A palliative care team is available at the request of the treating professional/team in all of the following settings: Day care (excluding palliative day care)

11 A palliative care team is available at the request of the treating professional/team in all of the following settings: At home (or home replacing institution s.a mental institution, prison)

12 A palliative care team is available at the request of the treating professional/team in all of the following settings: Hospital

13 A palliative care team is available at the request of the treating professional/team in all of the following settings: Hospice

14 A palliative care team is available at the request of the treating professional/team in all of the following settings: Care home

15 A palliative care team is available at the request of the treating professional/team in all of the following settings: Outpatient clinic (excluding palliative care outpatient clinic)

16 For every professional/team specialised palliative care advice is available 24 hours a day, 7 days a week

17 Patients in need of palliative care and their families have access to palliative care facilities: Throughout the entire duration of their disease

18 Patients in need of palliative care and their families have access to palliative care facilities: With no extra financial consequences for the patient

19 Patients receiving palliative care have access to diagnostic investigations (e.g. X-rays, blood samples) regardless of their setting

Primary care (Home, Nursing home)

20 Palliative care is available for the patient and their family by:Phone

21 Palliative care is available for the patient and their family by: Visiting the patient

22 Palliative care is available for the patient and their family by: Bringing the patient to the service

23 For a palliative patient in a crisis, the following can be arranged within 24 hours: Admission

24 For a palliative patient in a crisis, the following can be arranged within 24 hours: An urgent discharge to patients home

\begin{tabular}{|c|c|c|}
\hline $\begin{array}{l}\text { Structure } \\
\text { indicator }\end{array}$ & All settings & $\begin{array}{l}\text { New } \\
\text { developed }\end{array}$ \\
\hline $\begin{array}{l}\text { Structure } \\
\text { indicator }\end{array}$ & All settings & $\begin{array}{l}\text { New } \\
\text { developed }\end{array}$ \\
\hline $\begin{array}{l}\text { Structure } \\
\text { indicator }\end{array}$ & All settings & $\begin{array}{l}\text { New } \\
\text { developed }\end{array}$ \\
\hline $\begin{array}{l}\text { Structure } \\
\text { indicator }\end{array}$ & All settings & $\begin{array}{l}\text { New } \\
\text { developed }\end{array}$ \\
\hline $\begin{array}{l}\text { Structure } \\
\text { indicator }\end{array}$ & All settings & $\begin{array}{l}\text { New } \\
\text { developed }\end{array}$ \\
\hline $\begin{array}{l}\text { Structure } \\
\text { indicator }\end{array}$ & All settings & $\begin{array}{l}\text { New } \\
\text { developed }\end{array}$ \\
\hline $\begin{array}{l}\text { Structure } \\
\text { indicator }\end{array}$ & All settings & $\begin{array}{l}\text { New } \\
\text { developed }\end{array}$ \\
\hline $\begin{array}{l}\text { Structure } \\
\text { indicator }\end{array}$ & All settings & $\begin{array}{l}\text { New } \\
\text { developed }\end{array}$ \\
\hline
\end{tabular}

Process

All settings

New developed

Process

All settings

New developed

Process

indicator

All settings

New

developed

Process

indicator

All settings

New developed

Process

All settings

New

developed

Process

indicator

All settings

New

developed

Process

indicator

All settings

Process

indicator

All settings

New

developed

Process

indicator

All settings

Changed

Process

indicator

All settings

Process

indicator

All settings

Changed

Changed

$\begin{array}{lll}\begin{array}{l}\text { Process } \\ \text { indicator }\end{array} & \begin{array}{l}\text { Primary care } \\ \text { indicator }\end{array} & \text { Changed } \\ \text { Process } & \begin{array}{l}\text { Primary care } \\ \text { indicator }\end{array} & \text { Changed } \\ \text { Process } & \begin{array}{l}\text { Primary care } \\ \text { indicator }\end{array} & \text { Changed } \\ \text { indicator } & \text { Primary care } & \text { Changed } \\ \text { Process } & \text { Pricator } & \\ \text { indicator } & \text { indicator } & \\ \text { Process } & \text { Primary care } & \text { Changed } \\ \text { indicator } & \text { indicator } & \end{array}$




\section{Table 1 Quality indicator set (Continued)}

25 For a palliative patient in a crisis, the following can be arranged within 24 hours: Transfer to another setting of care

B. Out of hours (All settings)

Staff

26 A member of a palliative care team is available 24 hours a day, 7 days a week: For palliative care consultation by phone

27 A member of a palliative care team is available 24 hours a day, 7 days a week: To provide bedside care in a crisis

\section{Drugs}

28 The following treatments are available for a palliative patient 24 hours a day, 7 days a week: Opioids and other controlled drugs

29 The following treatments are available for a palliative patient 24 hours a day, 7 days a week: Anticipatory medication for the dying patient

30 The following treatments are available for a palliative patient 24 hours a day, 7 days a week: Syringe drivers

$$
\text { C. Continuity of care (All settings) }
$$

31 There is a procedure for exchange of clinical information across caregivers, disciplines and settings

32 Before discharge/transfer/admission there is information transfer to the caregivers in the next setting regarding care and treatment

33 There is a professional caregiver per individual palliative patient nominated as responsible 'key worker' who coordinates care

34 The responsible 'key worker' pays special attention to continuity of care within and across settings

Inpatient setting (Hospital, Palliative care unit, Hospice)

35 General practitioners (GP's) are routinely called when a patient is being discharged home or transferred to another setting

36 The discharge/transfer letter of palliative care patients contains a multidimensional diagnosis, prognosis and treatment plan (see indicator 48 Clinical record)

Primary care

37 The primary care out-of-hours service has handover forms (written or -electronic) with clinical information of all palliative care patients in the terminal phase at home

\section{Infrastructure \\ A. All settings \\ Infrastructure}

38 Specialist equipment (e.g. anti decubitus mattresses, aspiration material, stoma care, oxygen delivery, special drug administration pumps, hospital beds, etc.) is available for the nursing care of palliative care patients in each specific setting

39 There is a dedicated room where multidisciplinary team meetings within one setting takes place

40 There are dedicated facilities for multidisciplinary communications across settings: A dedicated room for meetings

41 There are dedicated facilities for multidisciplinary communications across settings: Facilities for video or telephone conferences

Information about care

42 There is an up to date directory of local caregivers and organisations that can have a role in palliative care

43 There are dedicated information about the palliative care service: A website

44 There are dedicated information about the palliative care service: Leaflets or brochures

45 Patient information should be available in relevant foreign languages
Process

indicator

Primary care

indicator

Changed

Process

indicator

All settings

Changed

Process

indicator

All settings

Changed

Structure

indicator

Primary care

indicator

Combined/

Structure

Primary care

Changed

indicator

indicator

Combined/

Structure

indicator

Primary care

Changed

indicator

Combined/

Changed

Process

indicator

All settings

Changed

Process

indicator

All settings

Changed

Process

indicator

All settings

Combined/

Changed

Process

All settings

Combined/

indicator

Changed

Process

indicator

Inpatient setting Changed

indicator

Structure

indicator

Inpatient setting Changed

indicator

Structure indicator

Primary care indicator

Changed

Structure

All settings

Changed

indicator

Structure

All settings

New indicator

All settings

developed

Structure

indicator

Structure

indicator

All settings

Changed

Structure

indicator

All settings

New developed

Structure

All settings

Changed

indicator

All settings

Changed

All settings

Changed

Structure

Changed

indicator 


\section{Table 1 Quality indicator set (Continued)}

46 Appropriately trained translators should be available if professional caregivers and patient or family members do not speak the same language

47 There is a computerised medical record, to which all professional caregivers involved in the care of palliative care patients have access: Within one setting

$$
\text { IT systems }
$$

48 There is a computerised medical record, to which all professional caregivers involved in the care of palliative care patients have access: Across different settings

B. Inpatient setting (Hospital, Palliative care unit, Hospice, Nursing home)

49 Consultations with the patient and/or family/informal caregivers are done in an environment where privacy is guaranteed (e.g. there is a dedicated room)

50 Dying patients are able to have a single bedroom if they want to

51 There are facilities for a relative to stay overnight

52 Family members and friends are able to visit the dying patient without restrictions of visiting hours

53 There is a private place (e.g. dedicated room) for saying goodbye to the deceased

\section{Home care}

54 For a palliative care patient staying at home there is the possibility, if needed, to provide someone (a volunteer or professional) to stay overnight if needed

\section{Assessment tools}

55 There is a holistic assessment of palliative care needs of patients and their family caregivers (e.g. SPARC)

56 There is an assessment of pain and other symptoms using a validated instrument

Personnel palliative care services

$$
\text { A. Staff }
$$

57 The multidisciplinary team that provides palliative care consists of at least one of the following disciplines: Physician

58 The multidisciplinary team that provides palliative care consists of at least one of the following disciplines: Nurse

59 The multidisciplinary team that provides palliative care consists of at least one of the following disciplines: Spiritual/religious caregiver

60 The multidisciplinary team that provides palliative care consists of at least one of the following disciplines: Psychologist/Psychiatrist

61 The multidisciplinary team that provides palliative care consists of at least one of the following disciplines: Social worker

62 The multidisciplinary team that provides palliative care consists of at least one of the following disciplines: Physiotherapist

63 The multidisciplinary team that provides palliative care consists of at least one of the following disciplines: Occupational therapist

64 The multidisciplinary team that provides palliative care consists of at least one of the following disciplines: Dietitian

65 The multidisciplinary team that provides palliative care consists of at least one of the following disciplines: Bereavement counselor

66 The multidisciplinary team that provides palliative care consists of at least one of the following disciplines: Pharmacist

B. Education and training for staff/volunteers

67 New staff receives a standardised induction training

68 All team members have certified (accredited?) training in palliative care, appropriate to their discipline
Process

indicator

Process indicator

All settings Combined

Changed

All settings

Process indicator

All settings

Combined

Structure indicator

Process

indicator

Structure

indicator

Process

indicator

Structure

indicator

Inpatient setting Changed

indicator

Inpatient setting New

indicator developed

Inpatient setting New

indicator developed

Inpatient setting Changed

indicator

Inpatient setting New

indicator

developed

Process

Home care

indicator

Changed

indicator

All settings

Changed

Process

indicator

All settings

Changed

Structure

indicator

All settings

Changed

Structure

indicator

All settings

Changed

Structure indicator

All settings

Changed

Structure

All settings

Changed

indicator

Structure

indicator

All settings

Changed

Structure indicator

All settings

Changed

Structure indicator

All settings

Changed

Structure indicator

All settings

Changed

Structure indicator

All settings

Changed

Structure indicator

All settings

Changed

Process indicator

All settings

Changed

Process

All settings

indicator
Changed 


\section{Table 1 Quality indicator set (Continued)}

69 All volunteers have training in palliative care.

C. Support systems

70 All team members have an annual appraisal

71 All team members who professionally deal with loss have access to a program for care for the carers

72 Satisfaction with working in the team is assessed (e.g. Team Climate Inventory)

\section{Organisation of care}

73 Palliative care services work in conjunction with the referring professional/team

74 There is a regular interdisciplinary/multi-professional meeting to discuss palliative care patients: daily meetings to discuss day-to- day management of palliative care patients

75 There is a regular interdisciplinary/multi-professional meeting to discuss palliative care patients: weekly (inter- and multidisciplinary) meeting to review palliative care patients referrals and care plans

\section{E. Information sharing}

76 All relevant team members are informed about patients who have died

\section{Documentation of clinical data}

\section{A. Clinical record (All settings)}

77 For patients receiving palliative care a structured palliative care clinical record is used

78 The palliative care clinical record contains evidence of documentation of the following items: Clinical summary

79 The palliative care clinical record contains evidence of documentation of the following items: Physical aspects of care

80 The palliative care clinical record contains evidence of documentation of the following items: Psychological and psychiatric aspects of care

81 The palliative care clinical record contains evidence of documentation of the following items: Social aspects of care

82 The palliative care clinical record contains evidence of documentation of the following items: Spiritual, religious, existential aspects of care

83 The palliative care clinical record contains evidence of documentation of the following items: Cultural aspects of care

84 The palliative care clinical record contains evidence of documentation of the following items: Care of imminently dying patient

85 The palliative care clinical record contains evidence of documentation of the following items: Ethical, legal aspects of care

86 The palliative care clinical record contains evidence of documentation of the following items: Multidimensional treatment plan

87 The palliative care clinical record contains evidence of documentation of the following items: Follow up assessment

B. Timely documentation
Process

indicator

All settings

Combined/

Changed

$\begin{array}{lll}\begin{array}{l}\text { Process } \\ \text { indicator }\end{array} & \text { All settings } & \text { Changed } \\ \begin{array}{l}\text { Process } \\ \text { indicator }\end{array} & \text { All settings } & \text { Changed } \\ \text { Process } & \text { All settings } & \text { Changed }\end{array}$

Process

indicator

Inpatient setting New

indicator developed

Process

indicator

All settings

Process

indicator

All settings

Combined/

Changed

Combined/

Changed

Process

indicator

Inpatient setting Changed

indicator

\begin{tabular}{|c|c|c|}
\hline $\begin{array}{l}\text { Process } \\
\text { indicator }\end{array}$ & All settings & Changed \\
\hline $\begin{array}{l}\text { Process } \\
\text { indicator }\end{array}$ & All settings & Changed \\
\hline $\begin{array}{l}\text { Process } \\
\text { indicator }\end{array}$ & All settings & Changed \\
\hline $\begin{array}{l}\text { Process } \\
\text { indicator }\end{array}$ & All settings & Changed \\
\hline $\begin{array}{l}\text { Process } \\
\text { indicator }\end{array}$ & All settings & Changed \\
\hline $\begin{array}{l}\text { Process } \\
\text { indicator }\end{array}$ & All settings & Changed \\
\hline $\begin{array}{l}\text { Process } \\
\text { indicator }\end{array}$ & All settings & Changed \\
\hline $\begin{array}{l}\text { Process } \\
\text { indicator }\end{array}$ & All settings & Changed \\
\hline $\begin{array}{l}\text { Process } \\
\text { indicator }\end{array}$ & All settings & Changed \\
\hline $\begin{array}{l}\text { Process } \\
\text { indicator }\end{array}$ & All settings & Changed \\
\hline Process & All settings & Changed \\
\hline
\end{tabular}

indicator

Inpatient setting (Hospital, Palliative care unit, Hospice, Nursing home)

88 Within 24 hours of admission there is documentation of the initial assessment of: Prognosis, Functional status, Pain and other symptoms, Psychosocial symptoms, The patient's capacity to make decisions

89 There is documentation that patients reporting pain or other symptoms at the time of admission, had their pain or other symptoms relieved or reduced to a level of their satisfaction within 48 hours of admission

90 There is documentation about the discussion of patient preferences within 48 hours of admission

$\begin{array}{lll}\begin{array}{l}\text { Process } \\ \text { indicator }\end{array} & \begin{array}{l}\text { Inpatient setting } \\ \text { indicator }\end{array} \\ \begin{array}{l}\text { Process } \\ \text { indicator }\end{array} & \begin{array}{l}\text { Inpatient setting } \\ \text { indicator }\end{array} \\ & \begin{array}{l}\text { Changed } \\ \text { Process } \\ \text { indicator }\end{array} & \begin{array}{l}\text { Inpatient setting } \\ \text { indicator }\end{array}\end{array}$




\section{Table 1 Quality indicator set (Continued)}

91 A discharge/transfer summary is available in the medical record within 48 hours after discharge/ Process transfer

$$
\text { All settings }
$$

92 There is documentation of pain assessment at 4 hour intervals

93 The discussion of patient's preferences is reviewed on a regular basis (in parallel with disease progression) or on request of the patient

94 There is documentation that within 24 hours after patient transfer, the responsible physician in the receiving setting has visited the patient

95 There is documentation that within 24 hours after patient transfer, the new palliative care team in the receiving setting has visited the patient

$$
\text { Quality and safety issues }
$$

$$
\text { A. Quality policies }
$$

96 The palliative care service has a quality improvement program

97 There is documentation whether targets set for quality improvement have been met

98 Clinical audit are part of the quality improvement program

99 The setting uses a program about early initiation of palliative care (e.g. the Gold Standards Framework)

\section{B. Adverse events}

100 There is a register for adverse events

101 There is a documented procedure to analyse and follow up adverse events

$$
\text { C. Complaints procedure }
$$

102 There is a patient complaints procedure

Reporting clinical activity of palliative care services

103 The palliative care service uses a database for recording clinical activity

104 The following is part of the database: Diagnosis, Date of diagnosis, Date of referral, Date of admission to the palliative care service, Date of death, Place of death, Preferred place of death

105 From the database the service is able to derive: Time from diagnosis to referral to palliative care, Time from referral to initiation of palliative care, Time from initiation of palliative care to death, Frequency of unplanned consultations with the out-of-hours service for palliative care patients who are at home, Frequency of unplanned hospital admissions of palliative care patients, Percentage of non-oncological patients receiving palliative care

106 Based on the database, an annual report is made about the service

\section{Research}

107 There is evidence that the palliative care service is involved in research in palliative care (e.g. authorship of publications, research grants)

\section{Education}

108 All health and social care students have standardised learning objectives for basic training in palliative care

109 All health and social care professionals have standardised learning objectives for continuing basic training in palliative care

110 There is a program for specialised training in palliative care for professionals working in a service that provides specialised palliative care

indicator

indicator

Inpatient setting Changed

indicator

$\begin{array}{llr}\begin{array}{l}\text { Process } \\ \text { indicator }\end{array} & \text { All settings } & \text { Changed } \\ \begin{array}{l}\text { Process } \\ \text { indicator }\end{array} & \text { All settings } & \text { Changed } \\ \begin{array}{l}\text { Process } \\ \text { indicator }\end{array} & \text { All settings } & \text { Changed } \\ \begin{array}{l}\text { Process } \\ \text { indicator }\end{array} & \text { All settings } & \text { Changed }\end{array}$

indicator

Process

indicator

Process

indicator

Process

indicator

Process

indicator

Process

indicator

Process

indicator

Process

indicato

Process

indicato

Process

indicator

Process

indicator

All settings

Process

indicator

All settings

Process

indicator

Process

indicator

Process

indicator
All settings

All settings

All settings
Changed

Changed

Changed

Changed

Changed

Changed

Changed

Changed

Changed

Changed

Changed

New developed

Changed

New developed

New developed 
3. Based on this meeting, adaptations were made and a new draft QI set was presented in the second steering group meeting in October.

\section{Results}

\section{Search flow}

The literature search resulted in 541 papers, including a previous systematic review on quality indicators for palliative care [8]. Most of the papers came from the database search $(n=527)$, followed by the hand search $(n=29)$ and least of grey literature search $(n=14)$.

In the screening process 16 duplicates were identified, and titles and abstracts of 511 papers were searched. Of these, 389 documents were excluded, as they did not contain QIs. Full papers were obtained of 122 publications, from which 63 papers were included; 57 resulting from the database search [12-68] and another six papers from the additional hand searches (Figure 1) [69-74].

\section{Results grey literature search}

The grey literature search yielded seven papers, deriving from Belgium, the Netherlands and the UK [9,75-80]. These sources included government sites, national health organisations and national institutes (Figure 1).
This additional search resulted in the development of 53 QIs, divided over almost all domains (see Additional file 1).

\section{QI development}

Sixhundred-thirtyfive QIs were derived from this literature review. After screening of duplicates, selecting process and structure QIs and combining QIs covering the same topic, the remaining 151 QIs were organised in the framework and discussed in the first steering group meeting. The two steering group meetings resulted in a reduction from 151 to 110 QIs (Additional file 1: Appendix C) (Figure 2). For instance the domain about finance QIs was excluded for the final set as the QIs were more useful on national level than in the setting specific palliative care institutions.

The rest of the QIs were distributed over the framework (Table 1) [10].

The majority of the 110 QIs were process QIs $(n=76)$, the other structure QIs $(\mathrm{n}=34)$. Some of the QIs $(\mathrm{n}=24)$ were only applicable in specific settings; ten in primary care, thirteen in inpatient settings and one in home care. The others were meant for all settings that deliver palliative care.

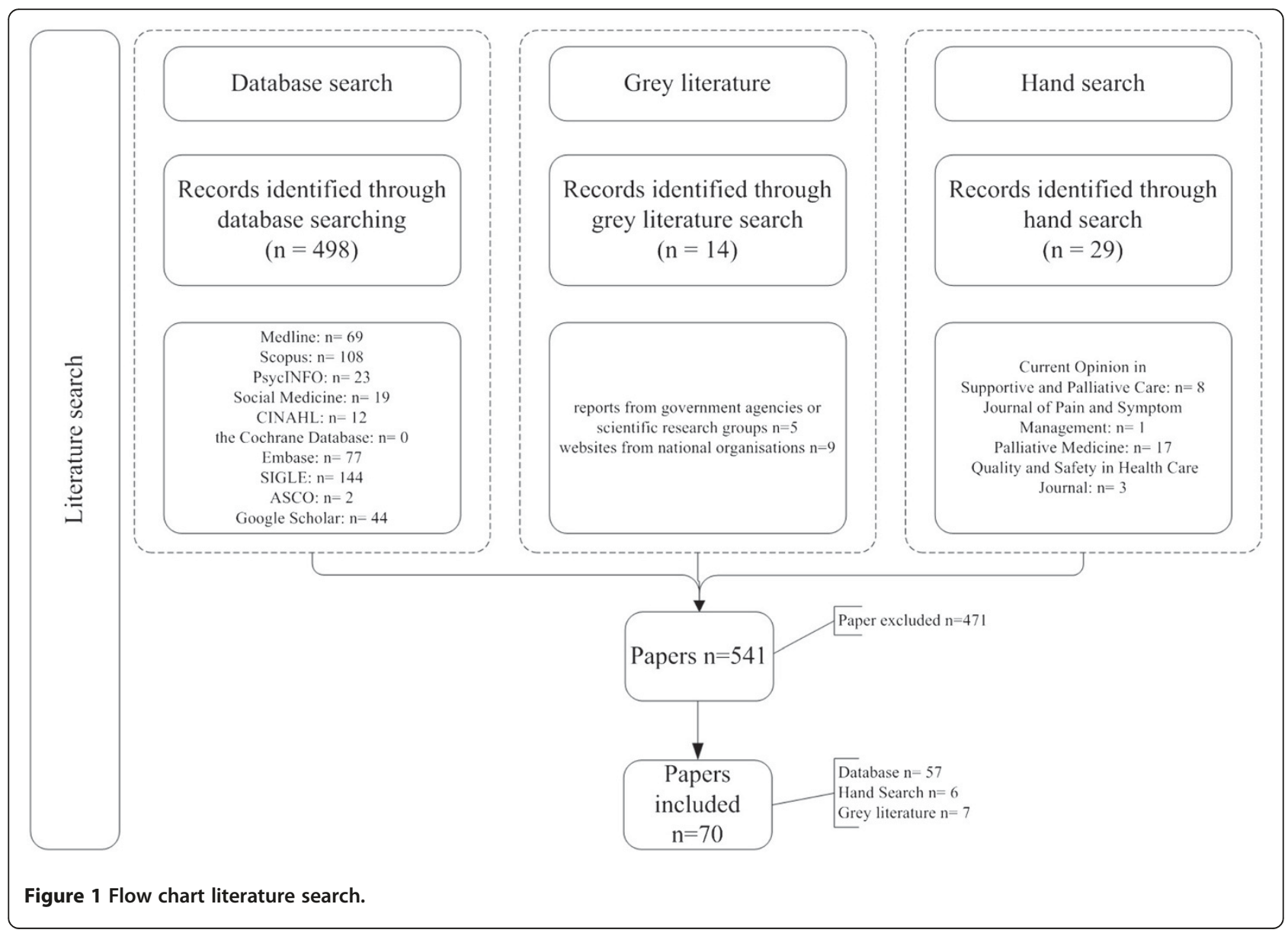




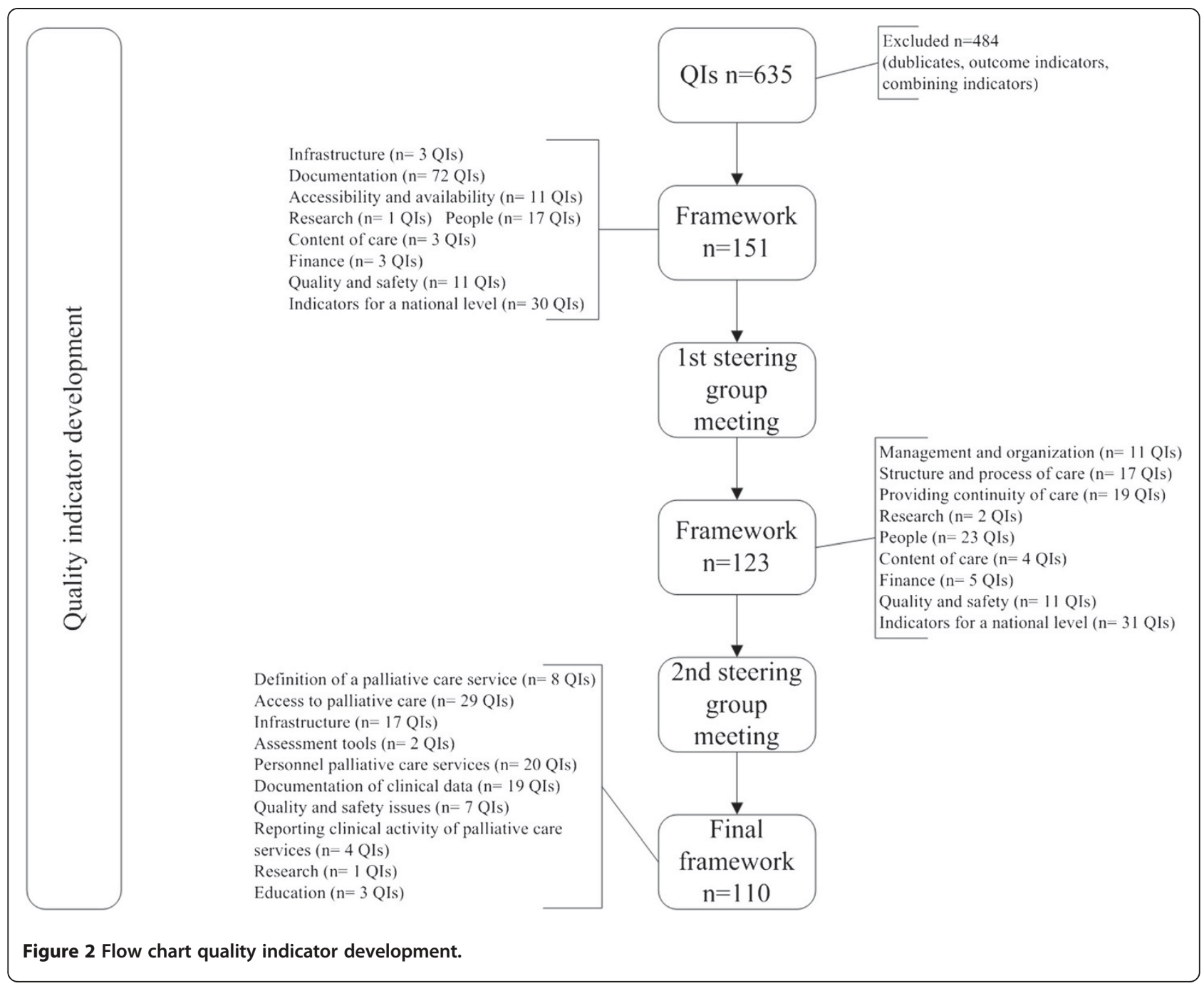

Twenty-four QIs were developed based on organisational aspects found in literature (Table 1, QI 51). Finally, several QIs $(n=86)$, were changed in their presentation of text during the procedure. For example, originally developed QIs for other settings like the intensive care unit, were adapted to make them appropriate for palliative care settings.

\section{Discussion}

We were able to develop an international framework with 110 QIs to assess the organisation of palliative care in several kind of settings. To our knowledge, this study presents the first systematically developed international set of QIs on this topic. Part of the QIs are setting specific, whereas others will be applicable in all kind of settings that deliver palliative care.

Where Pasman et al. performed a systematic review on all kind of QIs for palliative care, and Pastrana et al. focused on outcome indicators for Germany, we focused on process and structure QIs [8,81]. By using an international perspective and by not limiting the study to symptom control, our study follows the recommendations of Ostgathe et al. [82]. Our set also contains two QIs that are linked to the World Health Assembly's proposed global health indicator 'Access to palliative care assessed by morphine-equivalent consumption of strong opioid analgesia (excluding methadone) per death by cancer', but without the restriction to patients with cancer [83].

\section{Strength and limitations}

We chose an approach with several consecutive methodological steps to develop a set of QIs. Of those aspects that were considered important for the organisation of palliative care but of which no QIs could be found, we developed QIs ourselves [84]. Of those QIs that were developed for a restricted group of patients or setting (e.g. ICU or vulnerable elderly) we checked whether we could rephrase them into QIs for more types of settings or palliative patients. Defining QIs in a consensus procedure is a good 
option if scientific literature is not yet available [7], particularly because it combines several methods to improve validity. Using a group approach has the advantage that participants can share their expertise and experience. Groups often make better decisions than individuals [85].

The naming of QIs as process or structure indicators can be discussed. Yet, this only influences the categorisation and not the content, importance or use of a QI.

Another strong aspect of our procedure is the inclusion of grey literature, which created the possibility to include documents from important although not scientific sources [86].

As the Europall project was a collaboration of seven European countries, only experts of these countries were represented in the steering group meetings. Other European countries, with different health care and financing systems, cultures and palliative care, were not involved at this stage.

This first step resulted in a set of structure and process QIs, that can help professionals or settings to measure the quality of care of their setting. In a next step, a subset will be developed of which each QI is applicable in the seven participating countries.

Based on a modified RAND Delphi method the following set will be interesting for international comparison. The advantage of this comprehensive set enables each country and each setting the opportunity to see all QIs that are available on this topic.

The last step will describe a pilot study to test the set of QIs on face-validity, applicability and discriminative power. This includes almost all (26) European countries. These studies will be published separately.

\section{Further research}

The final set can be used to provide feedback to settings or countries to reflect on their performance, for supporting quality improvement activities, accreditation, research, and enhancing transparency about quality. They can be used to evaluate the implementation of the WHO definition and the recommendations of the council of Europe [1,4].

From 2011 to 2015, a follow-up project to Europall called IMPACT (funded by the EU $7^{\text {th }}$ framework) will develop and test strategies to implement these QIs.

\section{Conclusions}

This review resulted in the first comprehensive framework of QIs for the organisation of palliative care.

\section{Additional file}

Additional file 1: Supplementary online content. Development of a set of process and structure indicators for palliative care: the Europall project. Appendix A- Search strategies for databases. Appendix B- Project partners. Appendix C-Indicators set for the organisation of palliative care.

\section{Competing interest}

This work was partly funded by EAHC (Executive Agency for Health and Consumers, grant: 2006111 PPP 'Best practices in palliative care'). The funders had no role in study design, data collection and analysis, decision to publish, or preparation of the manuscript. The authors have no financial disclosures.

\section{Authors' contributions}

KvB participated in the literature search, design of the study and drafted the manuscript. NA participated in the literature search, design of the study and drafted the manuscript. JH participated in the literature search, design of the study and drafted the manuscript. JMM was actively involved in the selection and developmental process of the QI. She attended the expert meeting. IC was actively involved in the selection and developmental process of the QI. She attended the expert meeting. LR and helped to draft the manuscript and had an advisory role. KV conceived of the study and participated in its design and coordination and helped to draft the manuscript. YE conceived of the study and participated in its design and coordination and helped to draft the manuscript. All authors read and approved the final manuscript.

\section{Acknowledgements}

The authors are grateful to the EAHC (Executive Agency for Health and Consumers) for funding the Europall project. We would like to thank Hristina Mileva from EAHC specifically for her help and support. Further our thanks also go to the many individuals and organisations in the seven countries that contributed information to the project. We are especially grateful to all those who shared their views with us.

Belgium: Johan Menten

England: Sam Ahmedzai, Bill Noble

France: Jean-Christophe Mino

Germany: Eberhard Klaschik, Birgit Jaspers

Poland: Wojciech Leppert, Sylwia Dziegielewska

Spain: Xavier Gomez Batiste Alentorn, Silvia Paz, Marisa Martinez Munoz

\section{Author details}

${ }^{1}$ Department of Anaesthesiology, Pain and Palliative Medicine, Radboud University Nijmegen Medical Centre, Geert Grote Plein 10, Nijmegen 6500 $\mathrm{HB}$, The Netherlands. ${ }^{2}$ Department of Radiotherapy-Oncology and Palliative Medicine, University Hospital Leuven, Leuven, Belgium. ${ }^{3}$ Academic Unit of Supportive Care, School of Medicine and Biomedical Sciences, The University of Sheffield, Sykes House, Little Common Lane, Sheffield S11 9NE, UK. ${ }^{4}$ Department of Science and Research in Palliative Medicine, University of Bonn, Malteser Hospital Bonn/Rhein-Sieg, Bonn, Germany. ${ }^{5}$ Réseau de Santé, Paris Sud, France. 'Université Paris Descartes, Sorbonne Paris Cité, Public Health, Paris F-75006, France. ${ }^{7}$ AP-HP, Cochin Teaching Hospital, Palliative Medicine, Paris F-75014, France.

Received: 20 October 2011 Accepted: 31 October 2012

Published: 2 November 2012

\section{References}

1. WHO: Definition of Palliative Care. http://www.who.int/cancer/palliative/ definition/en/.

2. 10 facts on ageing and the life course. http://www.who.int/features/factfiles/ ageing/en/index.html.

3. What are the public health implications of global ageing? http://www.who. int/features/qa/42/en/index.html.

4. Recommendation Rec (2003) 24 of the Committee of Ministers to member states on the organisation of palliative care. http://www.coe.int/t/dg3/health/ Source/Rec(2003)24_en.pdf.

5. Smith TJ, Hillner BE: Ensuring quality cancer care by the use of clinical practice guidelines and critical pathways. J Clin Oncol 2001, 19:2886-2897.

6. Campbell SM, Ludt S, Van Lieshout J, Boffin N, Wensing M, Petek D, Grol R, Roland MO: Quality indicators for the prevention and management of cardiovascular disease in primary care in nine European countries. Eur J Cardiovasc Prev Rehabil 2008, 15:509-515. 
7. Campbell SM, Braspenning J, Hutchinson A, Marshall MN: Research methods used in developing and applying quality indicators in primary care. BMJ 2003, 326:816-819.

8. Pasman HRW, Brandt HE, Deliens L, Francke AL: Quality indicators for palliative care: a systematic review. J Pain Symptom Manage 2009, 38:145-156.

9. Europall Project. http://www.europall.eu/.

10. Engels $Y$, Campbell $S$, Dautzenberg $M$, van den Hombergh P, Brinkmann $H$, Szecsenyi J, Falcoff H, Seuntjens L, Kuenzi B, Grol R: Developing a framework of, and quality indicators for, general practice management in Europe. Fam Pract 2005, 22:215-222.

11. Cook AM, Finlay IG, Edwards AG, Hood K, Higginson IJ, Goodwin DM, Normand CE, Douglas HR: Efficiency of searching the grey literature in palliative care Journal of Pain and Symptom Management 2001, 22:797-801.

12. Aa Petersen $M$, Pedersen $L$, Groenvold M: Does the agreement of patient and physician assessments of health related quality of life in palliative care depend on patient characteristics? Palliat Med 2007, 21:289-294.

13. ASCO-ESMO: Consensus statement on quality cancer care. J Clin Oncol 2010, 24:3498-3499.

14. Becker G, Sarhatlic R, Olschewski M, Xander C, Momm F, Blum HE: End-oflife care in hospital: current practice and potentials for improvement. J Pain Symptom Manage 2007, 33:711-719.

15. Bottomley A: The journey of health-related quality of life assessment. Lancet Oncol 2008, 9:906.

16. Brumley R, Enguidanos S, Jamison P, Seitz R, Morgenstern N, Saito S, Mcllwane J, Hillary K, Gonzalez J: Increased satisfaction with care and lower costs: results of a randomized trial of in-home palliative care. J Am Geriatr Soc 2007, 55:993-1000.

17. Casarett D, Pickard A, Bailey FA, Ritchie C, Furman C, Rosenfeld K, Shreve S, Chen Z, Shea JA: Do palliative consultations improve patient outcomes? J Am Geriatr Soc 2008, 56:593-599.

18. Delgado-Guay MO, Parsons HA, Li Z, Palmer L, Bruera E: Symptom distress, interventions, and outcomes of intensive care unit cancer patients referred to a palliative care consult team. Cancer 2009, 115:437-445.

19. Demiris G, Oliver DP, Wittenberg-Lyles E: Assessing caregivers for team interventions (ACT): a new paradigm for comprehensive hospice quality care. Am J Hosp Palliat Care 2009, 26:128-134.

20. Dixon BK: Quality measures crafted for palliative. Hospice Medicine. Family Practice News 2007, 37:6

21. Dougherty E, Pierce B, Ma C, Panzarella T, Rodin G, Zimmermann C: Factors associated with work stress and professional satisfaction in oncology staff. Am J Hosp Palliat Care 2009, 26:105-111.

22. Dy SM, Shugarman LR, Lorenz KA, Mularski RA, Lynn J, for the RANDSouthern California Evidence-Based Practice Center: A systematic review of satisfaction with care at the end of life. J Am Geriatr Soc 2008, 56:124-129.

23. Gelfman LP, Meier DE, Morrison RS: Does palliative care improve quality? A survey of bereaved family members. J Pain Symptom Manage 2008, 36:22-28.

24. Gomez-Batiste X, Fontanals MD, Roca J, Borras JM, Viladiu P, Stjernsward J, Rius E: Catalonia WHO demonstration project on palliative care implementation 1990-1995: results in 1995. J Pain Symptom Manage 1996, 12:73-78.

25. Granda-Cameron C, Viola SR, Lynch MP, Polomano RC: Measuring patientoriented outcomes in palliative care: functionality and quality of life. Clin J Oncol Nurs 2008, 12:65-77.

26. Gries $C J$, Curtis JR, Wall RJ, Engelberg RA: Family member satisfaction with end-of-life decision making in the ICU. Chest 2008, 133:704-712.

27. Griffin JP, Koch KA, Nelson JE, Cooley ME: Palliative care consultation, quality-of-life measurements, and bereavement for end-of-life care in patients with lung cancer: ACCP evidence-based clinical practice guidelines (2nd edition). Chest 2007, 132:404S-422S

28. Grunfeld E, Lethbridge L, Dewar R, Lawson B, Paszat LF, Johnston G, Burge F, Mclntyre $P$, Earle CC: Towards using administrative databases to measure population-based indicators of quality of end-of-life care: testing the methodology. Palliat Med 2006, 20:769-777.

29. Hanratty $B$, Holland $P$, Jacoby $A$, Whitehead M: Financial stress and strain associated with terminal cancer-a review of the evidence. Palliat Med 2007, 21:595-607.

30. Hicks F, Rees E: A 'pain-free' death. Br Med Bull 2008, 88:23-41.

31. Irwin SA, Zurhellen CH, Diamond LC, Dunn LB, Palmer BW, Jeste DV, Twamley EW: Unrecognised cognitive impairment in hospice patients: a pilot study. Palliat Med 2008, 22:842-847.
32. Jarabek BR, Jama AA, Cha SS, Ruegg SR, Moynihan TJ, McDonald FS: Use of a palliative care order set to improve resident comfort with symptom management in palliative care. Palliat Med 2008, 22:343-349.

33. Jordhoy MS, Inger Ringdal G, Helbostad JL, Oldervoll L, Loge JH, Kaasa S: Assessing physical functioning: a systematic review of quality of life measures developed for use in palliative care. Palliat Med 2007, 21:673-682.

34. Jünger $S$, Pestinger $M$, Elsner $F$, Krumm N, Radbruch L: Criteria for successful multiprofessional cooperation in palliative care teams. Palliat Med 2007, 21:347-354

35. Kairuz TE, Gargiulo D, Bunt C, Garg S: Quality, safety and efficacy in the 'off-label' use of medicines. Curr Drug Saf 2007, 2:89-95.

36. Kapo J, Morrison LJ, Liao S: Palliative care for the older adult. J Palliat Med 2007, 10:185-209.

37. Kim Y, Given BA: Quality of life of family caregivers of cancer survivors: across the trajectory of the illness. Cancer 2008, 112:2556-2568.

38. Le BHC, Ashby MA: Audit of deaths and palliative care referrals in a large Australian teaching hospital. J Palliat Med 2007, 10:835-836.

39. Leonard M, Agar M, Mason C, Lawlor P: Delirium issues in palliative care settings. J Psychosom Res 2008, 65:289-298.

40. Lorenz K: Progress in measuring and improving palliative and end-of-life quality. J Palliat Med 2008, 11:682-684.

41. Mayadev AS, Weiss MD, Distad BJ, Krivickas LS, Carter GT: The amyotrophic lateral sclerosis center: a model of multidisciplinary management. Phys Med Rehabil Clin N Am 2008, 19:619-631.

42. McNiff KK, Neuss MN, Jacobson JO, Eisenberg PD, Kadlubek P, Simone JV: Measuring supportive care in medical oncology practice: lessons learned from the quality oncology practice initiative. J Clin Oncol 2008, 26:3832-3837

43. Meraviglia M, Sutter R, Gaskamp CD: Providing spiritual care to terminally ill older adults. J Gerontol Nurs 2008, 34:8-14.

44. Miller SC, Kiely DK, Teno JM, Connor SR, Mitchell SL: Hospice care for patients with dementia: does volume make a difference? J Pain Symptom Manage 2008, 35:283-291.

45. Miyashita M, Nakamura A, Morita T, Bito S: Identification of quality indicators of end-of-life cancer care from medical chart review using a modified Delphi method in Japan. Am J Hosp Palliat Care 2008, 25:33-38.

46. Norton SA, Hogan LA, Holloway RG, Temkin-Greener H, Buckley MJ, Quill TE: Proactive palliative care in the medical intensive care unit: effects on length of stay for selected high-risk patients. Crit Care Med 2007, 35:1530-1535.

47. van der Ploeg E, Depla MFIA, Shekelle P, Rigter H, Mackenbach JP: Developing quality indicators for general practice care for vulnerable elders; transfer from US to The Netherlands. Qual Saf Health Care 2008, 17:291-295.

48. Pronost A, Le Gouge ALD: The effects of various features of haematologyoncology services using the palliative approach and the sociodemographic characteristics of healthcare providers on health indicators: social support, perceived stress, coping strategies, quality of life at work. Oncology 2008, 10:125-134.

49. Quill TE: Is length of stay on hospice a critical quality of care indicator? J Palliat Med 2007, 10:290-292.

50. Ripamonti Cl: Malignant bowel obstruction: tailoring treatment to individual patients. J Support Oncol 2008, 6:114-115.

51. Robinson C, Pesut B, Bottorff J, Mowry A, Broughton S, Fyles G: Rural palliative care: a comprehensive review. J Palliat Med 2009, 12:253-258.

52. Rokoske FS, Schenck AHL: Developing Quality Measures for Hospice and Palliative Care. Gerontologist 2008, 48:691.

53. Sampson EL, Thune-Boyle I, Kukkastenvehmas R, Jones L, Tookman A, King M, Blanchard MR: Palliative care in advanced dementia; A mixed methods approach for the development of a complex intervention. BMC Palliat Care 2008, 7:8

54. Sato K, Miyashita M, Morita T, Sanjo M, Shima Y, Uchitomi Y: Reliability assessment and findings of a newly developed quality measurement instrument: quality indicators of end-of-life cancer care from medical chart review at a Japanese regional cancer center. J Palliat Med 2008, 11:729-737.

55. Sela RA: Screening for depression in palliative cancer patients attending a pain and symptom control clinic. Palliat Support Care 2007, 5:207-217.

56. Slaven M, Wylie N, Fitzgerald B, Henderson N, Taylor S: Who needs a palliative care consult?: the Hamilton Chart Audit tool. J Palliat Med 2007, 10:304-307. 
57. Smith AK, McCarthy EP, Paulk E, Balboni TA, Maciejewski PK, Block SD, Prigerson HG: Racial and ethnic differences in advance care planning among patients with cancer: impact of terminal illness acknowledgment, religiousness, and treatment preferences. J Clin Oncol 2008, 26:4131-4137.

58. van der Steen JT, Mitchell SL, Frijters DHM, Kruse RL, Ribbe MW: Prediction of 6-month mortality in nursing home residents with advanced dementia: validity of a risk score. J Am Med Dir Assoc 2007, 8:464-468.

59. Tei Y, Morita T, Nakaho T, Takigawa C, Higuchi A, Suga A, Tajima T, Ikenaga M, Higuchi H, Shimoyama N, Fujimoto M: Treatment efficacy of neural blockade in specialized palliative care services in Japan: a multicenter audit survey. J Pain Symptom Manage 2008, 36:461-467.

60. Teno JM, Connor SR: Referring a patient and family to high-quality palliative care at the close of "life: "We met a new personality... with this level of compassion and empathy". JAMA 2009, 301:651-659.

61. Teunissen SCCM, Verhagen EH, Brink M, van der Linden BA, Voest EE, de Graeff A: Telephone consultation in palliative care for cancer patients: 5 years of experience in The Netherlands. Support Care Cancer 2007, 15:577-582.

62. Torres-Vigil I, Aday LA: Health care providers' assessments of the quality of advanced-cancer care in Latin American medical institutions: a comparison of predictors in five countries: Argentina, Brazil, Cuba, Mexico, and Peru. J Pain Palliat Care Pharmacother 2008, 22:7-20.

63. Tsai LY, Li IF, Liu CP, Su WH, Change TY: Application of quality audit tools to evaluate care quality received by terminal cancer patients admitted to a palliative care unit. Support Care Cancer 2008, 16:1067-1074.

64. Tuffrey-Wijn I, Hogg JCL: End-of-life and palliative care for people with intellectual disabilities who have cancer or other life-limiting illness: a review of the literature and available resources. J Appl Res Intellect Disabil 2007, 20:331-344.

65. Walling A, Lorenz KA, Dy SM, Naeim A, Sanati H, Asch SM, Wenger NS: Evidence-based recommendations for information and care planning in cancer care. J Clin Oncol 2008, 26:3896-3902.

66. Wenig LC, Huang HL, Wilkie DJ, Hoenig NA, Suarez ML, Marschke M, Durham J: Predicting survival with the palliative performance scale in a minority-serving hospice and palliative care program. J Pain Symptom Manage 2009, 37:642-648.

67. Yao CA, Hu WY, Lai YF, Cheng SY, Chen CY, Chiu TY: Does dying at home influence the good death of terminal cancer patients? J Pain Symptom Manage 2007, 34:497-504.

68. Zib M, Saul P: A pilot audit of the process of end-of-life decision-making in the intensive care unit. Crit Care Resusc 2007, 9:213-218.

69. Costantini M: Editorial: place of death. It is time for a change of gear. Palliat Med 2008, 22:785-786.

70. Dudgeon DJ, Knott C, Eichholz M, Gerlach JL, Chapman C, Viola R, Van Dijk J, Preston S, Batchelor D, Bartfay E: Palliative Care Integration Project (PCIP) quality improvement strategy evaluation. J Pain Symptom Manage 2008, 35:573-582.

71. Glasgow JL, McLennan SR, High KJ, Celi LAG: Quality of dying in a New Zealand teaching hospital. Qual Saf Health Care 2008, 17:244-248.

72. Luthy C, Cedraschi C, Pautex S, Rentsch D, Piguet V, Allaz AF: Difficulties of residents in training in end-of-life care. A qualitative study. Palliat Med 2009, 23:59-65.

73. Rayner L, Loge JH, Wasteson E, Higginson IJ: The detection of depression in palliative care. Curr Opin Support Palliat Care 2009, 3:55-60.

74. Zaider T, Kissane D: The assessment and management of family distress during palliative care. Curr Opin Support Palliat Care 2009, 3:67-71.

75. Externe indicatoren voor pijn bij kanker. http://www.zichtbarezorg.nl/mailings/ FILES/htmlcontent/Ziekenhuizen/New\%202e\%20tranche/Pijn\%20bij\% 20 kanker\%20defnew\%20inc1\%20wijzigingen\%20nav\%20autorisatie.pdf.

76. Klinische kwaliteitsindicatoren. Objective Elements - Communication (OEC). Brussel: Federaal Kenniscentrum voor de gezondheidszorg (KCE). https://kce. fgov.be/sites/default/files/page_documents/d20061027343.pdf.

77. Improving Supportive and Palliative Care for Adults National Institute for Clinical Excellence with Cancer. http://www.nice.org.uk/nicemedia/live/10893/ 28816/28816.pdf.

78. Plan van Aanpak Palliatieve Zorg 2008-2010. http://www.palliatief.nl/ LinkClick.aspx?fileticket=yX68iRdBUjw\%3d\&tabid=3997\&mid=10542.

79. Quality and outcomes framework. http://www.paymodernisation.scot.nhs.uk/ gms/quality/docs/QualOutFrame0804.pdf.
80. Studie inzake de ontwikkeling van een registratie-instrument voor palliatieve zorg. http://www.palliatief.be/accounts/143/attachments/Research/ studie_registratie-instrument_pz_def.versie.pdf.

81. Pastrana T, Radbruch L, Nauck F, Hover G, Fegg M, Pestinger M, Ross J, Krumm N, Ostgathe C: Outcome indicators in palliative care-how to assess quality and success. Focus group and nominal group technique in Germany. Support Care Cancer 2010, 18:859-868.

82. Ostgathe C, Voltz R: Quality indicators in end-of-life care. Curr Opin Support Palliat Care 2010, 4:170-173.

83. Payne S, Leget C, Peruselli C, Radbruch L: Quality indicators for palliative care: debates and dilemmas. Palliat Med 2012, 26:679-680.

84. Claessen S, Francke A, Belarbi H, Pasman H, van der Putten M, Deliens L: A new set of quality indicators for palliative care: process and results of the development trajectory. J Pain Symptom Manage 2011, 42:169-182.

85. Mrowietz U, Kragballe K, Reich K, Spuls P, Griffiths C, Nast A, Franke J, Antoniou C, Arenberger P, Balieva F, Bylaite M, Correia O, Dauden E, Gisondi $P$, Iversen L, Kemeny L, Lahfa M, Nijsten T, Rantanen T, Reich A, Rosenbach T, Segaert S, Smith C, Talme T, Volc-Platzer B, Yawalkar N: Definition of treatment goals for moderate to severe psoriasis: a European consensus. Arch Dermatol Res 2010, 303:1-10.

86. Genet N, Boerma WG, Kringos DS, Bouman A, Francke AL, Fagerstrom C, Melchiorre MG, Greco C, Deville W: Home care in Europe: a systematic literature review. BMC Health Service Research 2011, 11:207.

doi:10.1186/1472-6963-12-381

Cite this article as: Woitha et al:: Development of a set of process and structure indicators for palliative care: the Europall project. BMC Health Services Research 2012 12:381.

\section{Submit your next manuscript to BioMed Central and take full advantage of:}

- Convenient online submission

- Thorough peer review

- No space constraints or color figure charges

- Immediate publication on acceptance

- Inclusion in PubMed, CAS, Scopus and Google Scholar

- Research which is freely available for redistribution 